\title{
The Dystonias: Past, Present and Future
}

\author{
H. A. Jinnah ${ }^{1}$, Mahlon DeLong ${ }^{2}$, and Mark Hallett ${ }^{3}$ \\ ${ }^{1}$ Departments of Neurology, Human Genetics \& Pediatrics, Emory University, Atlanta GA, USA \\ ${ }^{2}$ Department of Neurology, Pediatrics \& Psychiatry, Emory University, Atlanta GA, USA \\ ${ }^{3}$ Human Motor Control Section, National Institute of Neurological Disorders and Stroke, National \\ Institutes of Health, Bethesda MD, USA
}

\begin{abstract}
It has been just over 100 years since the term "dystonia" was coined by Oppenheim. ${ }^{1}$ Since then, there has been enormous progress. The first major meeting on dystonia was the International Dystonia Symposium in 1974 in New York, sponsored by the Dystonia Medical Research Foundation. It was at this meeting that Fahn and Eldridge proposed the first widely used definition and classification system for all dystonias. It also was at this meeting that Marsden proposed considering the focal dystonias as formes fruste of generalized dystonia, several families were described pointing to a genetic basis, and Sagawa presented his patients with dopa responsive dystonia outside of Japan. The proceedings were published in 1976 as volume 14 of Advances in Neurology. These symposia continued every few years, with proceedings of each meeting published in subsequent volumes of Advances in Neurology.
\end{abstract}

The $5^{\text {th }}$ International Dystonia Symposium was held in 2011 in Barcelona, under the joint sponsorship of the Dystonia Medical Research Foundation and The European Dystonia Federation. However, the progress became too much for a single meeting held every few years, and additional meetings were organized to address specific topics in dystonia including genetics, cell biology, anatomy, physiology and animal models. Other meetings focussed on experimental therapeutics or treatment, with the $2^{\text {nd }}$ International Congress on Treatment of Dystonia occurring this year in Hannover, Germany. The termination of the Advances in Neurology series combined with interest in reaching the widest possible audience, led to this Special Theme Issue on Dystonia. The purpose of this issue is to review some of the recent progress. It is not meant to serve as a comprehensive review of all research in dystonia. Instead, it focuses on current views and evolving concepts, the most challenging unanswered questions in dystonia research, and research priorities for the future.

The article by Albanese and colleagues ${ }^{2}$ summarizes the evolving clinical definitions and subtyping of dystonia, with a proposal for a modern definition and classification system that accommodates what has been learned since the proposal of Fahn and Eldridge. Bressmann and Saunders-Pullman ${ }^{3}$ describe the history of the concept of "primary" dystonias, which are labelled "isolated" dystonia syndromes in the new classification system. Frucht ${ }^{4}$ describes a practical approach for diagnosis of dystonia in the clinic, and Fung and colleagues ${ }^{5}$ provide comprehensive list of the myriads of syndromes where dystonia is mixed with other clinical features, together with a useful strategy based on syndromic patterns to aid in diagnosis. These more general articles are supplemented by articles on topics of particular importance such as the similarities and differences among adult-onset

Corresponding author: H. A. Jinnah, MD, PhD, Emory University School of Medicine, Departments of Neurology, Human Genetics \& Pediatrics, 6300 Woodruff Memorial Building, Atlanta GA, 30322, USA, Phone: 404-727-9107, Fax: 404-712-8576,

hjinnah@emory.edu. 
focal dystonias, ${ }^{6}$ specific problems in children with dystonia, ${ }^{7}$ and psychiatric comorbidities. ${ }^{8}$

Scientific progress also has increased dramatically in recent years, with four new genes for isolated dystonia syndromes being described in the past year alone. ${ }^{9}$ The identification of these and other genes means that it is now possible to begin to identify common molecular and cellular pathways in dystonia. ${ }^{10}$ Our understanding of the pathogenesis of dystonia has evolved from a focus on the basal ganglia to a broader network model that includes other regions. ${ }^{11}$ Specific physiological defects have emerged as potential endophenotypic traits that predispose individuals to develop dystonia. ${ }^{12}$ With this new perspective, we now are in a position to examine Marsden's original proposal that generalized and focal dystonias are related, ${ }^{6}$ and understand familial clustering. The article by Oleas and colleagues ${ }^{13}$ outlines the sometimes unexpected lessons we can learn from mouse models that have been genetically engineered as models of specific human dystonias, while the article by Wilson and colleagues describes insights that can be gained by exploiting phenotypic animal models that have a motor syndrome that fits clinical definitions of dystonia. ${ }^{14}$

The Special Theme Issue on Dystonia concludes with a focus on current treatments, their limitations, and ideas for experimental therapeutics. ${ }^{15,16}$ Currently, most of our treatments are empirically driven. However, the dramatic advances in our understanding of the pathogenesis of dystonia means that we now can begin to develop more targeted therapeutics. Many of the articles in this issue raise more questions than answers, so clearly there is a lot more work to do.

\section{Bibliography}

1. Klein C, Fahn S. Translation of Oppenheim's 1911 paper on dystonia. Mov Disord. 2013 This issue.

2. Albanese A, Bhatia K, Bressman SB, et al. Phenomenology and classification of dystonia: A consensus update. Mov Disord. 2013 this issue.

3. Bressman S, Saunders-Pullman R. Primary dystonia: moribund or viable. Mov Disord. 2013 This issue.

4. Frucht S. What is dystonia? A practical aproach for the clinician. Mov Disord. 2013 This issue.

5. Fung VS, Jinnah HA, Bhatia K, Vidailhet M. Assessment of the patient with dystonia: An update on dystonia syndromes. Mov Disord. 2013 this issue.

6. Jinnah HA, Berardelli A, Comella C, et al. The focal dystonias: current views and challenges for future research. Mov Disord. 2013 This issue.

7. Mink J. Special conerns in defining, studying, and treating dystonia in chlldren. Mov Disord. 2013 This issue.

8. Zurowski M, Marsh L, McDonald W. Psychiatric comorbidities in dystonia: Emerging concepts. Mov Disord. 2013 this issue.

9. Lohmann K, Klein C. Hereditary dystonia: What's new? What's next? Mov Disord. 2013 this issue.

10. LeDoux MS, Dauer WT, Warner T. Emerging molecular pathways for dystonia. Mov Disord. 2013 this issue.

11. Lehericy S. A current view of the anatomic basis of dystonia. Mov Disord. 2013 This issue.

12. Quartarone A, Hallett M. Emerging concepts in the physiological basis of dystonia. Mov Disord. 2013 this issue.

13. Oleas J, Yokoi FMPD, Pisani A, Li Y. Engineering animal models for dystonia: What have we learned? Mov Disord. 2013 this issue.

14. Wilson B, Hess EJ. Symptomatic animal models for dystonia. Mov Disord. 2013 This issue.

15. Moro E, Gross RE, Krauss JK. What's new in surgical treatments for dystonia? Mov Disord. 2013 This issue.

16. Jankovic J. Medical treatment of dystonia. Mov Disord. 2013 this issue. 